\title{
Population-based SEER trend analysis of overall crossuak and cancer-specific survival in 5138 patients with gastrointestinal stromal tumor
}

\author{
Ulrich Güller ${ }^{1,2^{*}}$, Ignazio Tarantino ${ }^{3}$, Thomas Cerny ${ }^{1}$, Bruno M. Schmied ${ }^{4}$ and Rene Warschkow ${ }^{4,5}$
}

\begin{abstract}
Background: The objective of the present population-based analysis was to assess survival patterns in patients with resected and metastatic GIST.

Methods: Patients with histologically proven GIST were extracted from the Surveillance, Epidemiology and End Results (SEER) database from 1998 through 2011. Survival was determined applying Kaplan-Meier-estimates and multivariable Cox-regression analyses. The impact of size and mitotic count on survival was assessed with a generalized receiver-operating characteristic-analysis.

Results: Overall, 5138 patients were included. Median age was 62 years (range: 18-101 years), $47.3 \%$ were female, $68.8 \%$ Caucasians. GIST location was in the stomach in $58.7 \%$ and small bowel in $31.2 \%$. Lymph node and distant metastases were found in 5.1 and $18.0 \%$, respectively. For non-metastatic GIST, three-year overall survival increased from $68.5 \%$ (95 \% Cl: 58.8-79.8 \%) in 1998 to $88.6 \%$ (95 \% Cl: 85.3-92.0 \%) in 2008, cancer-specific survival from $75.3 \%$ (95 \% Cl: 66.1-85.9 \%) in 1998 to $92.2 \%$ (95 \% Cl: 89.4-95.1 \%) in 2008. For metastatic GIST, three-year overall survival increased from $15.0 \%$ (95 \% Cl: 5.3-42.6\%) in 1998 to $54.7 \%$ (95 \% Cl: 44.4-67.3 \%) in 2008, cancer-specific survival from 15.0 \% (95 \% Cl: 5.3-42.6\%) in 1998 to $61.9 \%$ (95 \% Cl: 51.4-74.5 \%) in 2008 (all $P_{\text {Trend }}<0.05$ ).
\end{abstract}

Conclusions: This is the first SEER trend analysis assessing outcomes in a large cohort of GIST patients over a 11 -year time period. The analysis provides compelling evidence of a statistically significant and clinically relevant increase in overall and cancer-specific survival from 1998 to 2008, both for resected as well as metastatic GIST.

Keywords: Gastrointestinal stromal tumors (GIST), Surveillance, Epidemiology and End Results (SEER) database, Trend analysis, Gastric GIST

\section{Background}

Gastrointestinal stromal tumors (GIST) are the most frequent mesenchymal malignancies of the gastro-intestinal tract. The origin of GIST is the cell of Cajal, which is the pace-maker cell located between the circular and longitudinal muscle layer along the gastro-intestinal tract and is responsible for the gastro-intestinal motility. GIST occur most frequently in the stomach and small bowel, other locations such as esophagus, colon, rectum and extravisceral locations are rare.

\footnotetext{
* Correspondence: Ulrich.Gueller@kssg.ch

'Division of Medical Oncology \& Hematology, Kantonsspital St. Gallen, $\mathrm{CH}-9007$ St. Gallen, Switzerland

${ }^{2}$ University Clinic for Visceral Surgery and Medicine, University Hospital Berne, 3010 Berne, Switzerland

Full list of author information is available at the end of the article
}

For many decades surgery was the only efficient treatment modality for GIST. However, despite complete resection, the high recurrence rate remained an unsettling problem. The use of chemotherapy or radiation was proven to be largely ineffective [1]. However, over the past 15 years substantial improvements were made in the understanding of the pathogenesis and treatment of GIST. Around the change of millennium physicians began to understand that GIST are a result of a KIT or PDGFR mutation and more importantly, that the resulting mutated KIT or PDGF receptor could be blocked by the tyrosine kinase inhibitor imatinib. This targeted agent, which previously had a tremendous success in treating chronic myeloid leukemia by blocking the ABLkinase of the $B C R-A B L$ fusion protein, was now also 
applied in this solid tumor entity. Imatinib was first used in a female patient with a metastatic GIST, who was unsuccessfully treated with different chemotherapies [2]. After 4 weeks of imatinib treatment, a phenomenal response was seen on PET scan. Since then, many studies including several randomized trials have been performed using imatinib in non-metastatic [3, 4] and metastatic GIST [5, 6].

However, it remains unknown whether improvements in understanding and management of GIST patients have resulted in relevant patient benefits on a population-based level. Therefore, the primary objective of the present analysis was to assess whether overall and cancer-specific survival of GIST patients have improved over a 11-year time period.

\section{Methods}

\section{Cohort definition}

The recent ASCII text data-version of the Surveillance, Epidemiology, and End Results (SEER) Program of the National Cancer Institute in the United States, covering approximately $28 \%$ of cancer cases in the United States, was the source of present population-based analysis [7]. SEER data were collected and reported using data items and codes as documented by the North American Association of Central Cancer Registries (NAACCR) [8]. Primary cancer site and histology were coded according to criteria in the third edition of the International Classification of Diseases for Oncology (ICD-O-3) [9].

GIST patients were identified by the primary sites esophagus, stomach, small intestine, colon, rectum, appendix, peritoneum and the codes " 8935 " and "8936" for ICD-O-3 histology. Patients diagnosed at autopsy or by death certificate only as well as patients without histological confirmation were excluded (NAACCR Items 490 and 2180). Patients with other SEER reportable cancers were excluded unless the GIST was the first diagnosed malignancy (NAACCR Item 380) in order to use the cancer-specific survival. Patients with pediatric GIST $(\mathrm{n}=$ 24) were excluded from the analysis (Fig. 1). Size was coded as a continuous variable in $\mathrm{mm}$. Five patients with GIST sizes exceeding $70 \mathrm{~cm}$ were excluded from analyses involving GIST size.

\section{Statistical analysis}

Statistical analyses were performed using the $R$ statistical software (www.r-project.org). A two-sided p-value $<0.05$ was considered statistically significant. Continuous data are expressed as median and interquartile range (IQR). After descriptive analysis, survival was assessed by Kaplan-Meier analysis. Overall and cancer-specific survival were the designated endpoints. For analysis of overall survival, the time from diagnosis until the end of the follow-up was used

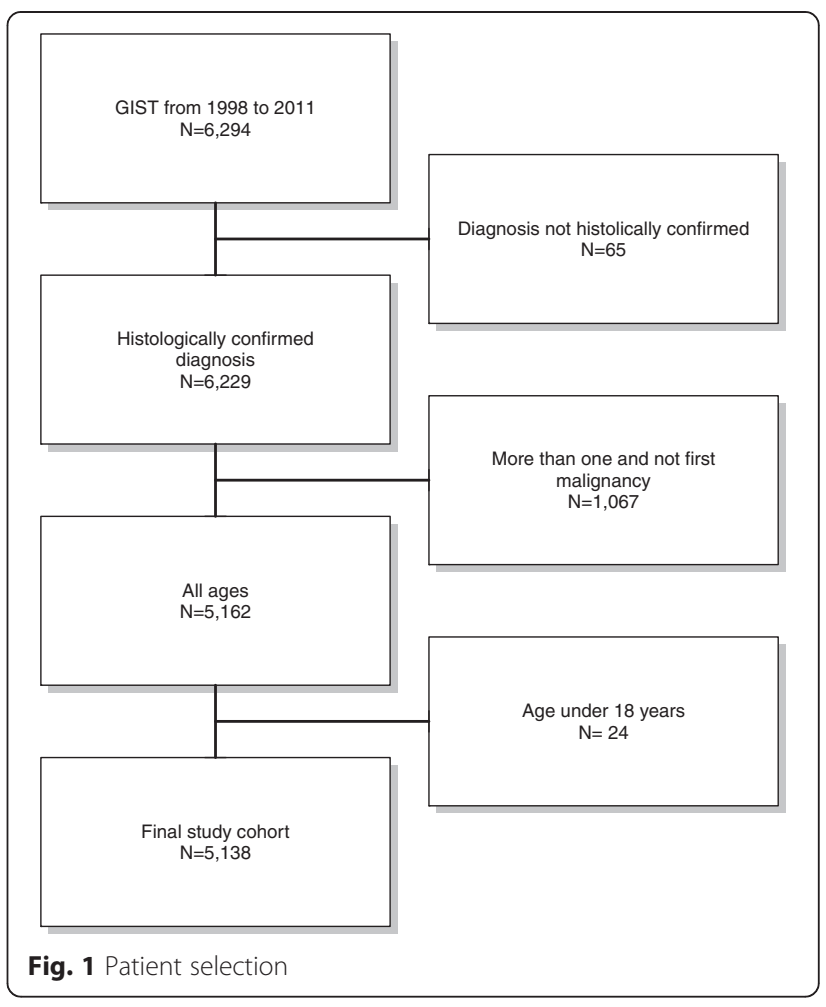

together with the information whether a patient died or not. For cancer-specific survival, cancer-associated deaths were counted for the estimation of the cancerspecific survival whereas other deaths unrelated to GIST were censored. The censoring was based on the coding of these endpoints in the SEER database (alive, cancer-associated death, other death). P-values were computed using Cox-regression and likelihood-ratiotests. To assess the association between GIST size and survival, locally weighted scatterplot smoothing (LOWESS)-Regression was performed [10]. To analyze the predictive value of the continuous variables size and mitotic rate for survival, a generalized receiveroperating characteristic (ROC)-methodology for survival analysis was applied [11]. Sensitivity and 1specificity for prediction of one-year survival were simultaneously plotted as ROC-curves and the area under the curve (AUC) was estimated. Mitotic count was systematically recorded after 2009, therefore only one year survival rates were computable. For each distinct value of mitotic count and size, the pairs of 'true positives' (number of patients for whom death was predicted and who died) and 'false positives' (number of patients for whom death was predicted and who survived) are displayed [11]. These pairs form the receiver-operating characteristic (ROC)curve. The area under the curve (AUC) of a perfect predictor would have an AUC of 1 and the ROCcurve would have an ROC plot along the left side 
and the top of the graph. For prediction due to chance, the AUC is 0.5 and the ROC-curves are on the diagonal line ("chance diagonal") [12]. The statistically optimal cut-off value was estimated by maximizing the Youden index (computed as Sensitivity + Specificity-1). Multivariable survival analyses were done using Cox regression analyses. The proportional hazard assumption was tested by scaled Schoenfeld residuals and by inspection of the hazard ratio (HR) plots [13]. For trend analysis, Spearman's rho was applied. Extrapolation of survival rates was based on the covariate vector for the year of diagnosis modeled as a factorial variable in Cox regression.

\section{Ethics statement}

This study was based on public use de-identified data from the SEER database and did not involve interaction with human subjects or use personal identifying information. The study did not require informed consent from the SEER registered cases and the authors obtained Limited-Use Data Agreements from SEER.

\section{Results}

\section{Patient characteristics}

Overall 5138 patients diagnosed with GIST between 1998 and 2011 in one of the regions covered by SEER were eligible for the present analysis (Fig. 1). The median follow-up in our patient cohort was 37 months (interquartile range: 14 to 74 months). The median age was 62 years (interquartile range 52 to 73 years) with a range of 18 to 101 years, $47.3 \%$ were female, $68.8 \%$ Caucasians. GISTs were located in the stomach in $58.7 \%$ and small bowel in $31.2 \%$. All other locations were rare (Table 1). Lymph node metastases were found in $5.1 \%$, distant metastases in $18.0 \%$ of all patients (Table 1). Median size of the GIST was $7.0 \mathrm{~cm}$ (interquartile range 4.5 to $11.8 \mathrm{~cm}$ ) with a range from 0.2 to $70 \mathrm{~cm}$.

\section{Univariable survival analysis}

At the end of follow-up 3545 (69.0\%) patients were alive, 1080 (21.0\%) died from GIST and 513 (10.0\%) died due to reasons which were not associated with the GIST according to the coding in the SEER database. In patients with non-metastatic GIST lymph node metastases were associated with a significantly decreased overall and cancer-specific survival $(\mathrm{P}<0.001$, Fig. 2 panel a and b). Overall and cancer-specific survival was significantly decreased in patients with metastatic GIST and further so in patients without surgery of the primary tumor $(\mathrm{P}<0.001$, Fig. 2 panel $\mathrm{c}$ and d). Larger tumors were associated with significantly worse survival: Five-year overall survival rates were 81,80 and $65 \%(\mathrm{P}<0.001)$ in GIST tumors $<5 \mathrm{~cm}$, $5-9.9 \mathrm{~cm}$ and $=>10 \mathrm{~cm}$, respectively. Five-year cancer-
Table 1 Patients' characteristics

\begin{tabular}{|c|c|c|}
\hline \multirow[t]{2}{*}{ Variable } & \multirow[t]{2}{*}{ Category } & \multirow{2}{*}{$\begin{array}{l}\text { All GIST } \\
(N=5138)\end{array}$} \\
\hline & & \\
\hline \multirow[t]{8}{*}{ Location } & Stomach & 3018 (58.7 \%) \\
\hline & Small intestine & $1603(31.2 \%)$ \\
\hline & Other: & $517(10.1 \%)$ \\
\hline & • Esophageal & $29(0.6 \%)$ \\
\hline & · Colon & $139(2.7 \%)$ \\
\hline & - Rectum & $172(3.3 \%)$ \\
\hline & - Appendix & $3(0.1 \%)$ \\
\hline & - Peritoneum & $174(3.4 \%)$ \\
\hline \multirow[t]{4}{*}{ Size categories } & $<5 \mathrm{~cm}$ & $1280(24.9 \%)$ \\
\hline & $5 \mathrm{~cm}-9.9 \mathrm{~cm}$ & $1678(32.7 \%)$ \\
\hline & $10 \mathrm{~cm}+$ & $1471(28.6 \%)$ \\
\hline & Unknown & $709(13.8 \%)$ \\
\hline \multirow[t]{2}{*}{ Size $(\mathrm{cm})$} & Median [IQR] & $\begin{array}{l}7.0 \mathrm{~cm}[4.5 \text { to } \\
11.8 \mathrm{~cm}]\end{array}$ \\
\hline & Range & $0.2-70 \mathrm{~cm}$ \\
\hline \multirow[t]{3}{*}{ N stage } & $\mathrm{N}-$ & $4071(79.2 \%)$ \\
\hline & $\mathrm{N}+$ & $264(5.1 \%)$ \\
\hline & NX & $803(15.6 \%)$ \\
\hline \multirow[t]{4}{*}{ Mitotic Count ${ }^{a}$} & $<2$ per $50 \mathrm{HPF}$ & $397(7.7 \%)$ \\
\hline & 2-5 per $50 \mathrm{HPF}$ & $171(3.3 \%)$ \\
\hline & $>5$ per $50 \mathrm{HPF}$ & 159 (3.1\%) \\
\hline & Unknown & $4411(85.9 \%)$ \\
\hline \multirow{3}{*}{$\begin{array}{l}\text { Surgery of } \\
\text { primary }\end{array}$} & No surgery of primary tumor & 865 (16.8 \%) \\
\hline & Surgery of primary tumor & $4263(83.0 \%)$ \\
\hline & Unknown & $10(0.2 \%)$ \\
\hline \multirow[t]{5}{*}{ Metastatic disease } & Mo & $4211(82.0 \%)$ \\
\hline & M1: & 927 (18.0 \%) \\
\hline & $\begin{array}{l}-\mathrm{M} 1 \text {, no surgery of } \\
\text { metastasis }\end{array}$ & $-763(14.8 \%)$ \\
\hline & $-\mathrm{M} 1$, surgery of metastasis & $-139(2.7 \%)$ \\
\hline & $\begin{array}{l}\text {-M1, surgery of metastasis } \\
\text { unknown }\end{array}$ & $-25(0.5 \%)$ \\
\hline \multirow[t]{4}{*}{ Year } & 1998 to 2002 & $1120(21.8 \%)$ \\
\hline & 2003 to 2005 & $1195(23.3 \%)$ \\
\hline & 2006 to 2008 & 1227 (23.9\%) \\
\hline & 2009 to 2011 & 1596 (31.1\%) \\
\hline \multirow[t]{2}{*}{ Gender } & Male & 2709 (52.7 \%) \\
\hline & Female & $2429(47.3 \%)$ \\
\hline \multirow[t]{4}{*}{ Age } & $<50$ & 1060 (20.6 \%) \\
\hline & $50-64$ & 1805 (35.1 \%) \\
\hline & $65-79$ & 1682 (32.7 \%) \\
\hline & $80+$ & 591 (11.5 \%) \\
\hline Ethnicity & Caucasian & 3536 (68.8 \%) \\
\hline
\end{tabular}


Table 1 Patients' characteristics (Continued)

\begin{tabular}{lll}
\hline & African-American & $920(17.9 \%)$ \\
Marital status & Other/Unknown & $682(13.3 \%)$ \\
& Married & $3008(58.5 \%)$ \\
& Single & $832(16.2 \%)$ \\
Cause of death & Other/Unknown & $1298(25.3 \%)$ \\
& Alive & $3545(69.0 \%)$ \\
& Dead from cancer & $1080(21.0 \%)$ \\
Follow-up & Dead not from cancer & $513(10.0 \%)$ \\
(months) & Median [IQR] & $37.0[14.0$ to 74.0$]$ \\
\hline
\end{tabular}

${ }^{a}$ Mitotic count systematically recorded after 2009

specific survival rates were 92,87 and $72 \%$ in the respective size categories $(P<0.001$, Fig. 2 panel e and $f)$.

\section{Tumor size and mitotic count}

Figure 3 displays the GIST size (panel b) and its association with overall and cancer-specific survival (panel a) in patients with non-metastatic disease. The size distribution peaks at $5 \mathrm{~cm}$. For sizes exceeding $8 \mathrm{~cm}$ a marked decrease in overall and cancer-specific survival was observed for non-metastic GIST patients.

Figure 4 displays the predictive value of mitotic count (panel a) and tumor size (panel b) for one-year cancer-specific survival using the ROC-methodology. The impact of size on survival is lower compared to the mitotic count (area under the curve of $0.63 \mathrm{com}$ pared to 0.77). The statistically optimal (defined as maximal Youden index) cut-off value of mitotic count was 5 in 50 high power fields (HPF). For GIST size, the statistically optimal cut-off is $8 \mathrm{~cm}$. Similar results were obtained for overall survival (Fig. 5). The predictive value of mitotic count (panel a) was higher than the predictive value of the tumor size (panel b). The impact on overall survival was lower than on cancer-specific survival considering the lower area under the curve observed for mitotic count and for tumor size.

\section{Multivariable survival analysis}

In multivariable analysis of overall survival GIST location other than stomach and small bowel (hazard ratio (HR) 1.30, $\mathrm{P}=0.002)$, tumor size above $10 \mathrm{~cm}(\mathrm{HR} 1.63$; $P<0.001)$, presence of distant (HR 2.03; $\mathrm{P}<0.001)$ and lymph node metastases (HR 1.47; $\mathrm{P}=0.001$ ), older age $(P<0.001)$, single marital status (HR 1.38; $\mathrm{P}<0.001)$, and African-American ethnicity (HR 1.22; $\mathrm{P}=0.002)$ were associated with worse overall survival, whereas patients undergoing primary tumor excision (HR 0.49; $\mathrm{P}<0.001$ ), female patients (HR 0.70; $\mathrm{P}<0.001$ ), and patients during later time periods $(\mathrm{P}<0.001)$ had significantly improved overall survival (Table 2). Similar results were obtained for the cancer-specific survival except for African-American ethnicity (HR 1.08; P = 0.058) (Table 2).

\section{Trend analysis}

Overall survival in four different time periods is displayed in Fig. 6 for the entire patient cohort (panel a), as well as for non-metastatic (panel b) and metastatic (panel c) GIST patients. There has been a significant improvement in overall survival over time (all GIST: $P_{\text {Trend }}<0.001$, non-metastatic GIST: $P_{\text {Trend }}=$ 0.001, and metastatic GIST: $\left.P_{\text {Trend }}=0.013\right)$. The overall three-year survival for all GIST patients increased from $57.4 \%$ (95 \% CI: 48.3 to $68.2 \%$ ) in 1998 to $82.7 \%$ (95 \% CI: 79.1 to $86.3 \%$ ) in 2008. For nonmetastatic GIST, the overall three-year survival increased from $68.5 \%$ (95 \% CI: 58.8 to $79.8 \%$ ) in 1998 to 88.6 \% (95 \% CI: 85.3 to $92.0 \%$ ) in 2008 and for metastatic GIST from $15.0 \%$ (95 \% CI: 5.3 to $42.6 \%$ ) in 1998 to $54.7 \%$ (95\% CI: 44.4 to $67.3 \%$ ) in 2008. The annual percent change in three-year overall survival from 1999 to 2008 in all GIST patients was 11.9, 11.1, 0.6, 1.4, 1.9, 1.6, 4.9,-1.4,-0.1, and $4.1 \%$. In accordance with the hazard ratios and their confidence intervals for the year of diagnosis in the multivariable analysis (Table 2), most of the increase in the survival occurred in all sub-groups during the time before 2002. This is further depicted in panel $\mathrm{d}$ additionally demonstrating extrapolated estimates for the overall survival after 2008.

Figure 7 displays the Kaplan-Meier curves for cancerspecific survival for all patients (panel a), for nonmetastatic (panel b) and metastatic (panel c) GIST patients for the same time intervals. The cancer-specific survival significantly improved over time (all GIST: $\mathrm{P}_{\text {Trend }}<0.001$, non-metastatic GIST: $\mathrm{P}_{\text {Trend }}=0.001$, and metastatic GIST: $\left.\mathrm{P}_{\text {Trend }}=0.013\right)$. The three-year cancerspecific survival increased from $62.5 \%$ (95 \% CI: 53.4 to $73.2 \%$ ) in 1998 to $87.1 \%$ (95 \% CI: 83.9 to $90.3 \%$ ) in 2008 for all GIST patients, from $75.3 \%$ (95 \% CI: 66.1 to $85.9 \%$ ) in 1998 to $92.2 \%$ (95 \% CI: 89.4 to $95.1 \%$ ) in 2008 in non-metastatic GIST and from $15.0 \%$ (95 \% CI: 5.3 to $42.6 \%$ ) in 1998 to $61.9 \%$ (95\% CI: 51.4 to $74.5 \%$ ) in 2008 for metastatic GIST patients. The annual percent change for the three-year cancer-specific survival from 1999 to 2008 in the entire cohort was 16.1, $6.5,1.5,-0.8,3.9,1.1,2.4,-2.0,1.3$, and $2.4 \%$. Hence, the improvement in cancer-specific survival occurred mainly before 2002.

\section{Discussion}

This is the first population-based trend analysis of GIST patients over an 11-year time period. The present study 

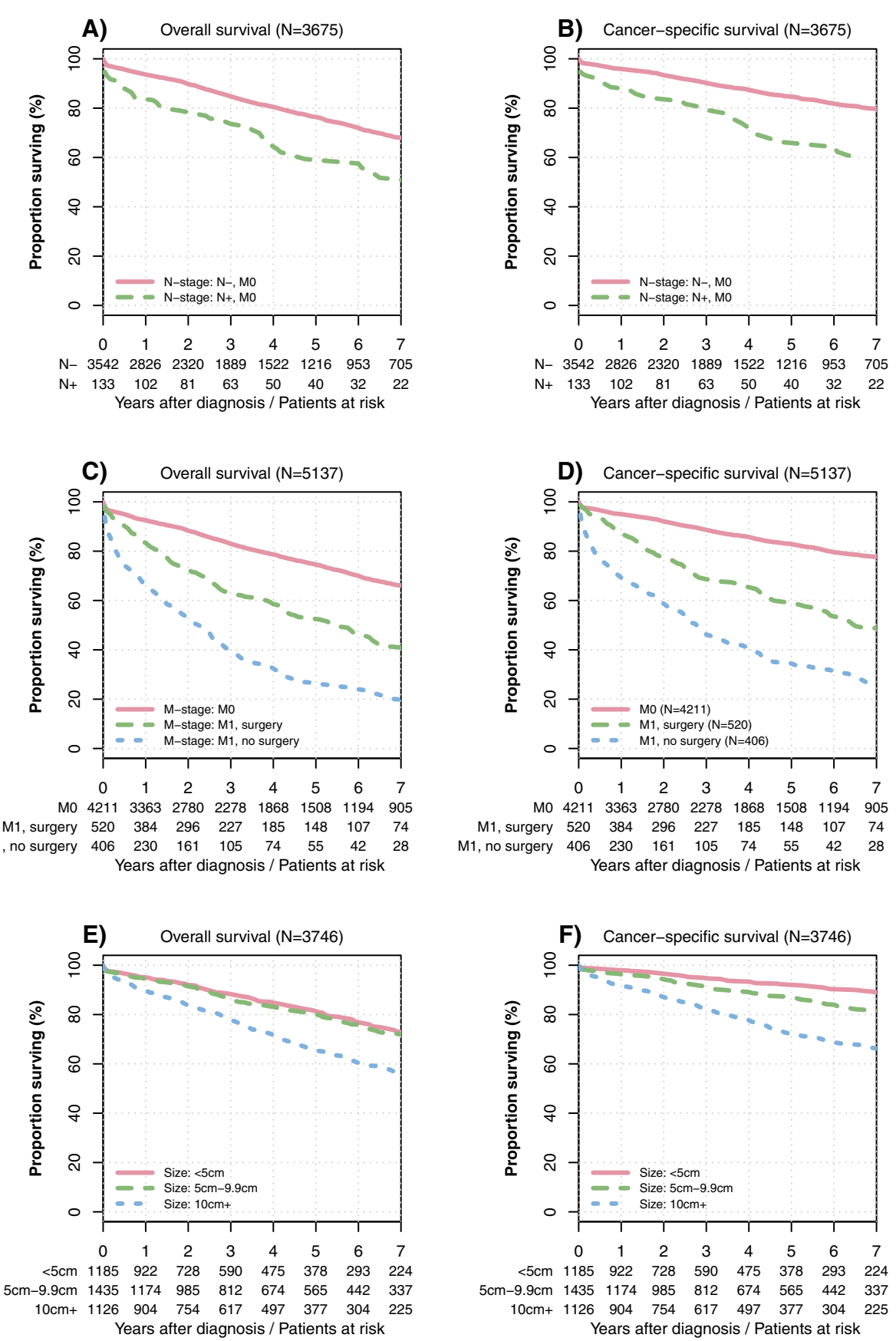

Fig. 2 Univariate survival analysis. The upper two plots display the Kaplan-Meier curves for overall (panel a) and cancer-specific survival (panel b) in $\mathrm{CMO}$ patients with and without lymph node metastases $(P<0.001)$. Panel $(\mathbf{c})$ and $(\mathbf{d})$ display the Kaplan-Meier curves in the overall cohort comparing patients with non-metastatic and with metastatic GIST who did and did not undergo primary tumour surgery $(P<0.001$ for all comparisons). Panel (e) and (f) display the Kaplan-Meier curves for non-metastatic GIST patients according to different primary tumour sizes ( $<5$ cm vs. 5 to $9.9 \mathrm{~cm}: \mathrm{P}=0.360$ for overall survival, all other comparisons: $\mathrm{P}<0.001$ ). Numbers of patients at risk are given below the $x$-axis

provides compelling evidence of a statistically significant and clinically relevant overall and cancer-specific survival increase from 1998 to 2008 , both in non-metastatic
GIST as well as metastatic GIST. In addition to the wellknown poor prognostic factors such as larger tumor size, nodal or distant metastases, and older age, we found that 


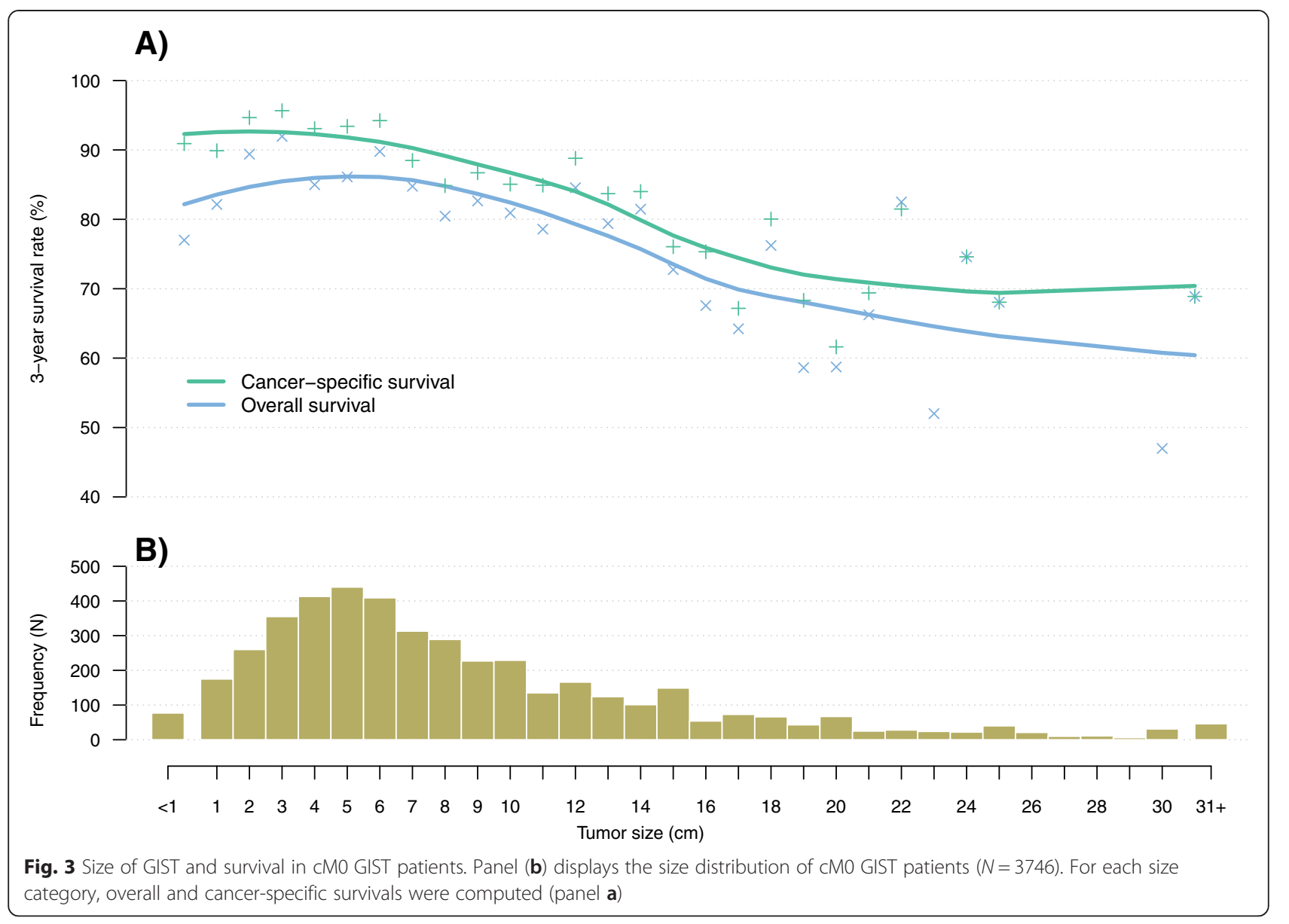

earlier time point of diagnosis, male gender, and single marital status are associated with worse overall and cancer-specific survival.

The present trend analysis was based on over 5000 GIST patients from the SEER registry. In this real-world analysis overall 3-year overall survival increased from $15 \%$ in 1998 to $55 \%$ in 2008 in metastatic GIST and from 68 to $89 \%$ in patients with non-metastatic GIST. There are several reasons for this substantial improvement. First, a large increase in overall and cancer-specific survival was observed during

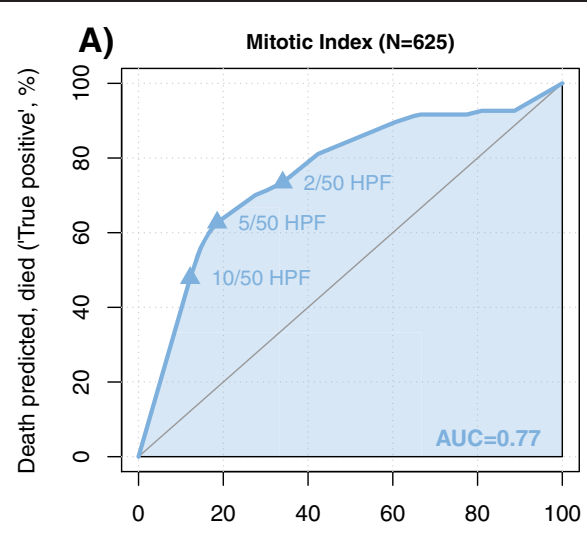

Death predicted, survived ('False positive', \%)
B)

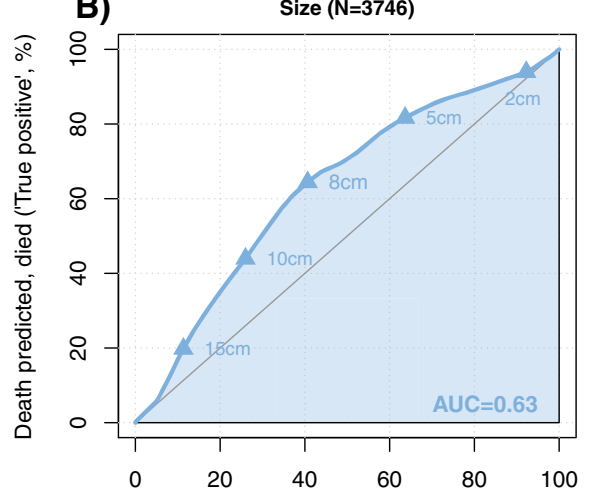

Death predicted, survived ('False positive', \%)

Fig. 4 Predictive value of mitotic count and size for one year cancer-specific survival in CMO GIST patients. On panel (a), the predictive value of mitotic count for one year cancer-specific survival is depicted. On panel (b), the predictive value of the size of the GIST is demonstrated 

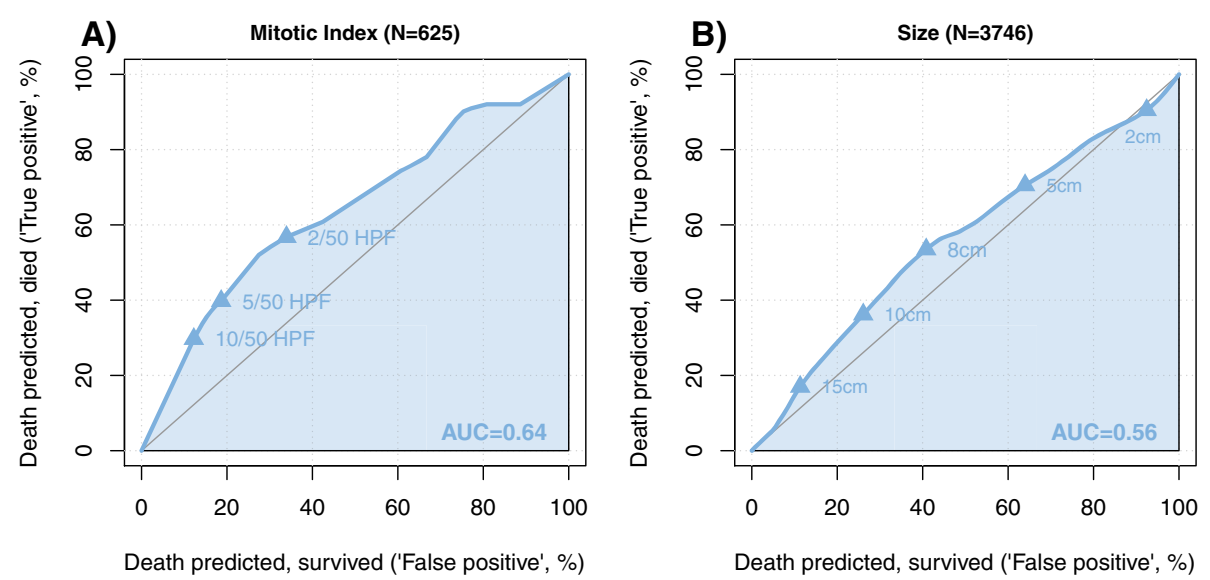

Fig. 5 Predictive value of mitotic count and size for one year overall survival in CMO GIST patients. On panel (a), the predictive value of mitotic count for one year overall survival is depicted. On panel (b), the predictive value of the size of the GIST for one year overall survival is demonstrated

the first 4 years of our analysis (1998-2001). This was prior to the FDA approval of imatinib. One explanation is that very low risk GIST may have been misclassified as leiomyoma and hence were not included into our analysis prior to the GIST consensus meeting of 2001 [14, 15]. Perez and colleagues showed a significant increase in reported GIST incidence from 1992 to 2002 based on SEER data, which is almost certainly related to reclassification of various tumors (e. g. leiomyoma) as GIST. [16] The inclusion of these tumors may have falsely increased the incidence and survival of GIST patients [17]. In the early years of our SEER analysis, the pivotal role of CD117 immunostaining was not systematically performed as previously pointed out by Tran and colleagues [18]. Hence, the incidence of GIST patients reported in SEER may be lower compared to studies, for which CD 117 staining was mandatory. Another explanation of the survival increase seen in the metastatic and non-metastatic group in the present analysis is stage migration. Indeed, PET scanning became a popular tool in the evaluation of GIST patients in the early and mid-2000's, potentially leading to stage migration (Will Rogers phenomenon). Another explanation of the improved outcomes seen in the present investigation may the introduction of imatinib and other tyrosine kinase inhibitors in GIST treatment. There is no doubt that the advent of imatinib in treating GIST represents an important step forward in cancer care as this targeted therapy-already very successful in patients with chronic myeloid leukemia-was now being applied for the first time to a solid gastrointestinal cancer. Over the past decade, several randomized controlled trials investigating imatinib were performed demonstrating improved outcomes in patients with completely resected $[3,4]$ and metastatic GIST $[5,6]$. While there are currently no other drugs than imatinib being used in non-metastatic GIST, several tyrosine kinase inhibitors have been associated with increased overall survival in patients with metastatic GIST. In addition to imatinib, which is used as a first line treatment, sunitinib [19] and regorafenib [20] have been evaluated in phase III randomized trials and resulted in an overall (sunitinib) and progression-free survival benefit (regorafenib) in second and third line treatment. Unfortunately, the use of tyrosine kinase inhibitors is not coded in the SEER database and hence an association between use of these systemic treatments and improved outcomes remains speculative.

Therefore, with more efficacious treatment options in advanced GIST patients, it is expected that overall and cancer-specific survival will continue to increase in the coming years as also shown in a data extrapolation in the present study (Fig. 5). In the adjuvant setting, the outcomes will most likely improve as well. In 2012, the German/Scandinavian study by Joensuu and colleagues provided compelling evidence that high-risk GIST patients have a better progression-free and overall survival with three years of adjuvant imatinib compared to only one year [4]. It is well known and also clearly seen in the German/Scandinavian trial that most recurrences occur within the first 12-24 months after stopping imatinib. Currently large randomized studies are undertaken to prove the hypothesis that 5 years of adjuvant imatinib treatment is superior to three years in the high-risk GIST subset. Selected patients with high-risk features (e. g. gastric GIST with very high mitotic count or non-gastric GIST with high mitotic count) may even benefit from life-long adjuvant imatinib treatment. However, this remains to be 
Table 2 Univariable and multivariable analysis of overall and cancer-specific survival

\begin{tabular}{|c|c|c|c|c|c|c|c|c|c|}
\hline \multirow{3}{*}{ Covariates } & & \multicolumn{4}{|l|}{ Overall survival } & \multicolumn{4}{|c|}{ Cancer-specific survival } \\
\hline & & \multicolumn{2}{|l|}{ Unadjusted $^{a}$} & \multicolumn{2}{|c|}{ Cox regression, full model $^{b}$} & \multicolumn{2}{|l|}{ Unadjusted $^{a}$} & \multicolumn{2}{|c|}{ Cox regression, full model } \\
\hline & & HR (95 \% Cl) & $p^{c)}$ & HR (95 \% Cl) & $p^{c)}$ & HR (95 \% Cl) & $p^{c)}$ & HR (95 \% Cl) & $p^{c)}$ \\
\hline \multirow[t]{3}{*}{ Location } & Stomach & Reference & $<0.001$ & Reference & 0.002 & Reference & $<0.001$ & Reference & $<0.001$ \\
\hline & Small intestine & $0.87(0.78-0.97)$ & & $0.98(0.87-1.10)$ & & $0.90(0.78-1.03)$ & & $0.96(0.83-1.11)$ & \\
\hline & Other & $1.31(1.13-1.53)$ & & $1.30(1.12-1.52)$ & & $1.54(1.30-1.84)$ & & $1.46(1.22-1.74)$ & \\
\hline \multirow[t]{4}{*}{ Size } & $<5 \mathrm{~cm}$ & Reference & $<0.001$ & Reference & $<0.001$ & Reference & $<0.001$ & Reference & $<0.001$ \\
\hline & $5 \mathrm{~cm}-9.9 \mathrm{~cm}$ & $1.13(0.97-1.32)$ & & $1.04(0.89-1.21)$ & & $1.52(1.23-1.89)$ & & $1.38(1.12-1.72)$ & \\
\hline & $10 \mathrm{~cm}+$ & $1.94(1.68-2.25)$ & & $1.63(1.40-1.89)$ & & $3.15(2.58-3.85)$ & & $2.52(2.05-3.08)$ & \\
\hline & Unknown & $2.36(2.01-2.78)$ & & $1.49(1.25-1.78)$ & & $3.72(2.99-4.62)$ & & $2.00(1.58-2.52)$ & \\
\hline \multirow[t]{2}{*}{ Metastatic disease } & MO & Reference & $<0.001$ & Reference & $<0.001$ & Reference & $<0.001$ & Reference & $<0.001$ \\
\hline & M1 & $2.84(2.56-3.16)$ & & $2.03(1.80-2.28)$ & & $3.69(3.26-4.17)$ & & $2.42(2.11-2.78)$ & \\
\hline \multirow[t]{3}{*}{ N stage } & $\mathrm{N}-$ & Reference & $<0.001$ & Reference & 0.001 & Reference & $<0.001$ & Reference & 0.001 \\
\hline & $\mathrm{N}+$ & $2.28(1.89-2.74)$ & & $1.47(1.21-1.79)$ & & $2.73(2.20-3.38)$ & & $1.55(1.24-1.93)$ & \\
\hline & NX & $1.83(1.63-2.05)$ & & $1.09(0.96-1.24)$ & & $2.12(1.85-2.42)$ & & $1.16(1.00-1.36)$ & \\
\hline Surgery of the & No surgery primary & Reference & $<0.001$ & Reference & $<0.001$ & Reference & $<0.001$ & Reference & $<0.001$ \\
\hline \multirow[t]{2}{*}{ primary } & Surgery primary & $0.33(0.29-0.36)$ & & $0.49(0.43-0.56)$ & & $0.27(0.24-0.31)$ & & $0.44(0.38-0.52)$ & \\
\hline & Unknown & $0.87(0.36-2.09)$ & & $1.36(0.56-3.31)$ & & $0.90(0.34-2.42)$ & & $1.36(0.50-3.67)$ & \\
\hline \multirow[t]{4}{*}{ Year } & 1998 to 2002 & Reference & $<0.001$ & Reference & $<0.001$ & Reference & $<0.001$ & Reference & $<0.001$ \\
\hline & 2003 to 2005 & $0.79(0.70-0.90)$ & & $0.76(0.67-0.86)$ & & $0.76(0.66-0.88)$ & & $0.73(0.63-0.85)$ & \\
\hline & 2006 to 2008 & $0.67(0.58-0.77)$ & & $0.61(0.53-0.71)$ & & $0.66(0.56-0.79)$ & & $0.63(0.53-0.75)$ & \\
\hline & 2009 to 2011 & $0.63(0.53-0.76)$ & & $0.62(0.51-0.75)$ & & $0.55(0.44-0.69)$ & & $0.55(0.44-0.70)$ & \\
\hline \multirow[t]{2}{*}{ Gender } & Male & Reference & $<0.001$ & Reference & $<0.001$ & Reference & 0.001 & Reference & $<0.001$ \\
\hline & Female & $0.79(0.72-0.88)$ & & $0.70(0.63-0.78)$ & & $0.81(0.72-0.92)$ & & $0.77(0.68-0.88)$ & \\
\hline \multirow[t]{4}{*}{ Age } & $<50$ & Reference & $<0.001$ & Reference & $<0.001$ & Reference & $<0.001$ & Reference & $<0.001$ \\
\hline & $50-64$ & $1.27(1.08-1.50)$ & & $1.40(1.19-1.66)$ & & $1.00(0.83-1.19)$ & & $1.11(0.92-1.33)$ & \\
\hline & $65-79$ & $2.25(1.92-2.63)$ & & $2.64(2.25-3.10)$ & & $1.54(1.29-1.83)$ & & $1.83(1.53-2.18)$ & \\
\hline & $80+$ & $4.92(4.15-5.83)$ & & $5.64(4.70-6.76)$ & & $2.91(2.39-3.55)$ & & $3.19(2.58-3.95)$ & \\
\hline \multirow[t]{3}{*}{ Ethnicity } & Caucasian & Reference & 0.001 & Reference & 0.002 & Reference & 0.013 & Reference & 0.058 \\
\hline & African-American & $1.19(1.06-1.35)$ & & $1.22(1.07-1.39)$ & & $1.15(0.99-1.34)$ & & $1.08(0.92-1.27)$ & \\
\hline & Other/Unknown & $0.86(0.74-1.01)$ & & $0.88(0.76-1.03)$ & & $0.82(0.68-1.00)$ & & $0.83(0.68-1.00)$ & \\
\hline \multirow[t]{3}{*}{ Marital status } & Married & Reference & $<0.001$ & Reference & $<0.001$ & Reference & $<0.001$ & Reference & $<0.001$ \\
\hline & Single & $1.18(1.03-1.36)$ & & $1.38(1.19-1.59)$ & & $1.29(1.10-1.53)$ & & $1.40(1.18-1.66)$ & \\
\hline & Other/Unknown & $1.48(1.32-1.66)$ & & $1.19(1.05-1.35)$ & & $1.44(1.25-1.65)$ & & $1.22(1.05-1.42)$ & \\
\hline
\end{tabular}

Hazard ratios (HR) with $95 \%$ confidence intervals

anivariate Cox regression analysis

${ }^{b}$ multivariable Cox regression analysis full model including all covariates depicted in the table rows on the left

clikelihood ratio tests

proven in well-designed and well-conducted trials as well as large cohort studies.

Both size and mitotic rate-the two best-known risk factors for recurrence-were evaluated in receiver operating curves in the present study. We identified a cut-off value of $8 \mathrm{~cm}$ and a mitotic rate of 5 per 50 high power fields (HPF) to be most predictive for cancer-specific survival. While the 5 mitosis per $50 \mathrm{HPF}$ is a largely used cut-off value to risk stratify GISTs [21], a size cutoff value for worse prognosis set at $5 \mathrm{~cm}$ may be overly pessimistic (Fig. 4). Indeed, in an investigation by Woodall et al., which analysed GIST tumours based on SEER data from 1974 through 2004, a size cut-off of $7 \mathrm{~cm}$ was identified as an independent poor prognostic factor [22]. 


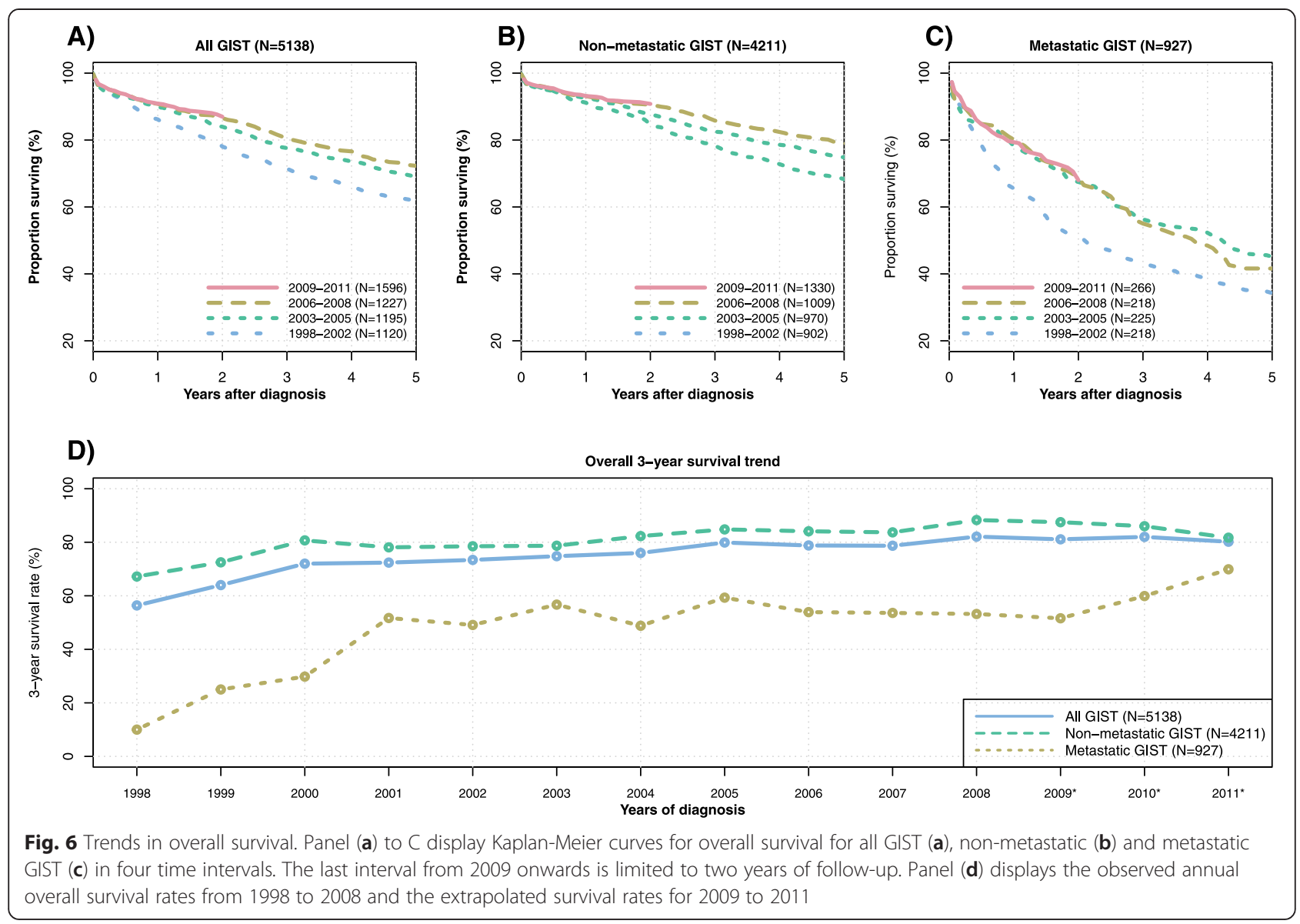

Moreover, in both univariate and multivariable analyses, a GIST size above $10 \mathrm{~cm}$ was associated with worse cancer-specific and overall survival while patients with GIST size between 5-10 cm had similar outcomes compared to those with a size of $5 \mathrm{~cm}$ and below. There is no doubt that a risk categorization of continuous biological variables such as size and mitotic rate is problematic. In this regard, prognostic contour maps as described by Joensuu et al. are helpful in assessing the risk of recurrence in GIST patients [23].

In the present analysis, patients with small bowel GIST had no worse overall and cancer-specific survival compared to patients with gastric GIST. This is opposed to other studies [24]. It is unclear why such a discrepancy occurs, however, may be due to different time periods in which the patients were enrolled in our study compared to the one by Gold and colleagues [24].

We would like to acknowledge the limitations of this study. The main drawback of this analysis is the lack of information on tyrosine kinase inhibitors used, data that cannot be ascertained in the SEER registry. Similarly, information about comorbidities, performance status, and information on site and number of metastases are not available in the SEER database. In addition, there is a relevant number of missing values for certain parameters e. g. mitotic rate, which was only systematically collected in the SEER database starting 2010. Despite these limitations, the present study has a variety of strengths. First, the population-based nature of the registry mirrors the real-world outcomes for GIST patients and is associated with a high degree of generalizability. It is key to evaluate to which extend advances in often highly selected patients in randomized controlled trials have translated into the overall patient population. Second, our study reports overall and cancer-specific survival data on a 11-years time period with extrapolation to a 14-years period. Third, the large sample size is associated with a high degree of power.

\section{Conclusion}

In conclusion, larger tumor size, location other than stomach or small bowel, nodal or distant metastases, older age, earlier time point of diagnosis, male gender 

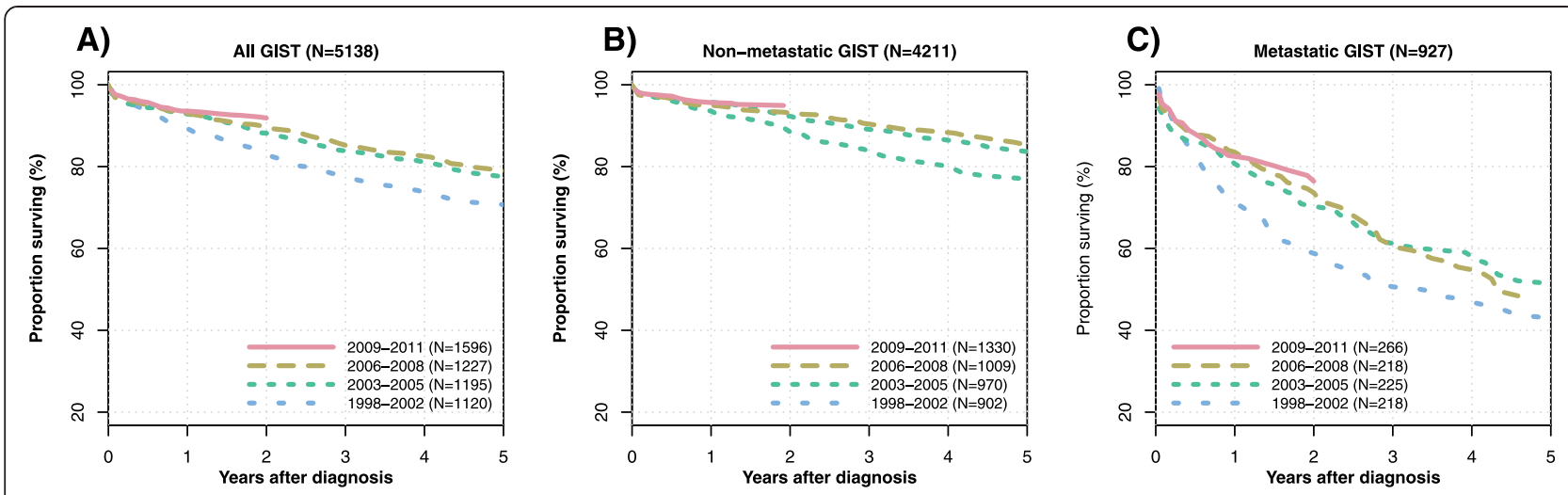

D)

Cancer-specific 3-year survival trend

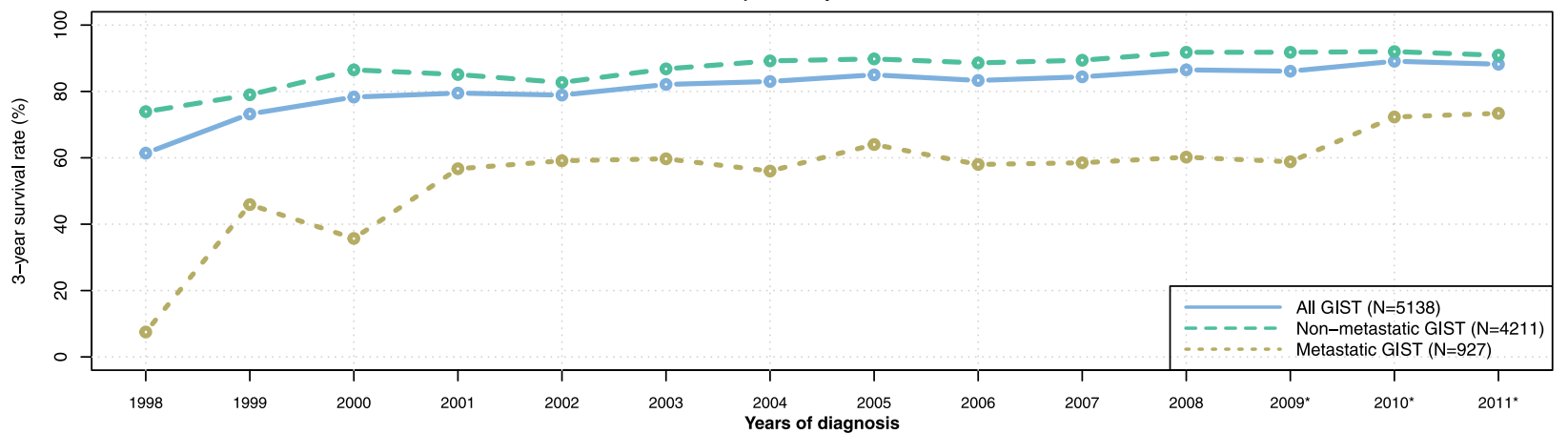

Fig. 7 Trends in cancer-specific survival. Panel (a) to (c) display Kaplan-Meier curves for cancer-specific survival for all GIST (a), non-metastatic (b) and metastatic GIST (c) in four time intervals. The last interval from 2009 onwards is limited to two years of follow-up. Panel (d) displays the observed annual cancer-specific survival rates from 1998 to 2008 and the extrapolated survival rates for 2009 to 2011

and single marital status are associated with significantly worse overall and cancer-specific survival. There has been a substantial increase in overall and cancer-specific survival from 1998 to 2008. It is anticipated that the current availability of different tyrosine kinase inhibitors in the advanced setting and better selection of high-risk patients benefitting from long-term adjuvant imatinib will continue to lead to a further improvement in patient outcomes.

\section{Competing interests}

The authors declare that they have no competing interests.

\section{Authors' contributions}

UG: Study design, interpretation of the data analysis, literature search, figures, manuscript writing, reviewing of manuscript. IT: Interpretation of the data analysis, literature search, figures, manuscript writing, reviewing of the manuscript. TC: Study design, manuscript writing, reviewing the manuscript. BMS: Study design, manuscript writing, reviewing the manuscript. RW: Study design, performing data analysis, interpretation of the data analysis, literature search, manuscript writing, reviewing of manuscript. All authors read and approved the final manuscript.

\section{Author details}

${ }^{1}$ Division of Medical Oncology \& Hematology, Kantonsspital St. Gallen,

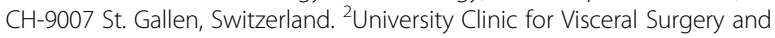

Medicine, University Hospital Berne, 3010 Berne, Switzerland. ${ }^{3}$ Department of General, Abdominal and Transplant Surgery, University of Heidelberg, 69120 Heidelberg, Germany. ${ }^{4}$ Department of Surgery, Kantonsspital St. Gallen, 9007 St. Gallen, Switzerland. Institute of Medical Biometry and Informatics, University of Heidelberg, 69120 Heidelberg, Germany.

Received: 16 December 2014 Accepted: 14 July 2015

Published online: 30 July 2015

\section{References}

1. Joensuu H, Fletcher C, Dimitrijevic S, Silberman S, Roberts P, Demetri G. Management of malignant gastrointestinal stromal tumours. Lancet Oncol. 2002:3(11):655-64.

2. Joensuu H, Roberts PJ, Sarlomo-Rikala M, Andersson LC, Tervahartiala P, Tuveson D, et al. Effect of the tyrosine kinase inhibitor STI571 in a patient with a metastatic gastrointestinal stromal tumor. N Engl J Med. 2001;344(14):1052-6.

3. Dematteo RP, Ballman KV, Antonescu CR, Maki RG, Pisters PW, Demetri GD, et al. Adjuvant imatinib mesylate after resection of localised, primary gastrointestinal stromal tumour: a randomised, double-blind, placebo-controlled trial. Lancet. 2009:373(9669):1097-104.

4. Joensuu H, Eriksson M, Sundby HK, Hartmann JT, Pink D, Schutte J, et al. One vs three years of adjuvant imatinib for operable gastrointestinal stromal tumor: a randomized trial. JAMA. 2012;307(12):1265-72.

5. Blanke CD, Rankin C, Demetri GD, Ryan CW, von Mehren M, Benjamin RS, et al. Phase III randomized, intergroup trial assessing imatinib mesylate at two dose levels in patients with unresectable or metastatic gastrointestinal stromal tumors expressing the kit receptor tyrosine kinase: S0033. J Clin Oncol. 2008;26(4):626-32. 
6. Verweij J, Casali PG, Zalcberg J, LeCesne A, Reichardt P, Blay JY, et al. Progression-free survival in gastrointestinal stromal tumours with high-dose imatinib: randomised trial. Lancet. 2004;364(9440):1127-34.

7. National Cancer Institute: Surveillance, Epidemiology, and End Results Program (SEER) Research Data (1973-2011) released April 2014, based on the November 2013 submission. www.seer.cancer.gov (Last accessed July 4, 2014) 2014.

8. Wingo PA, Jamison PM, Hiatt RA, Weir HK, Gargiullo PM, Hutton M, et al. Building the infrastructure for nationwide cancer surveillance and control-a comparison between the National Program of Cancer Registries (NPCR) and the Surveillance, Epidemiology, and End Results (SEER) Program (United States). Canc Causes Contr. 2003;14(2):175-93.

9. Fritz A, Percy C, Jack A. International classification of diseases for oncology: ICD-O, vol. 3. Geneva (Switzerland): World Health Organization; 2000.

10. Cleveland WS, Devlin SJ. Locally-weighted regression: an approach to regression analysis by local fitting. J Am Stat Assoc. 1988;83(403):596-610.

11. Heagerty PJ, Lumley T, Pepe MS. Time-dependent ROC curves for censored survival data and a diagnostic marker. Biometrics. 2000;56(2):337-44.

12. Hanley JA, McNeil BJ. The meaning and use of the area under a receiver operating characteristic (ROC) curve. Radiology. 1982;143(1):29-36.

13. Grambsch PM, Therneau TM. Proportional hazards tests and diagnostics based on weighted residuals. Biometrika. 1994;81(3):515-26.

14. Fletcher CD, Berman JJ, Corless C, Gorstein F, Lasota J, Longley BJ, et al. Diagnosis of gastrointestinal stromal tumors: a consensus approach. Hum Pathol. 2002;33(5):459-65

15. Rubio J, Marcos-Gragera R, Ortiz MR, Miro J, Vilardell L, Girones J, et al. Population-based incidence and survival of gastrointestinal stromal tumours (GIST) in Girona, Spain. Eur J Cancer. 2007:43(1):144-8

16. Perez EA, Livingstone AS, Franceschi D, Rocha-Lima C, Lee DJ, Hodgson N, et al. Current incidence and outcomes of gastrointestinal mesenchymal tumors including gastrointestinal stromal tumors. J Am Coll Surg. 2006;202(4):623-9.

17. Rubio-Casadevall J, Borras JL, Carmona C, Ameijide A, Osca G, Vilardell L, et al. Temporal trends of incidence and survival of sarcoma of digestive tract including Gastrointestinal Stromal Tumours (GIST) in two areas of the north-east of Spain in the period 1981-2005: a population-based study. Clin Transl Oncol. 2014;16(7):660-7.

18. Tran T, Davila JA, El-Serag HB. The epidemiology of malignant gastrointestinal stromal tumors: an analysis of 1,458 cases from 1992 to 2000. Am J Gastroenterol. 2005;100(1):162-8.

19. Demetri GD, van Oosterom AT, Garrett CR, Blackstein ME, Shah MH, Verweij $J$, et al. Efficacy and safety of sunitinib in patients with advanced gastrointestinal stromal tumour after failure of imatinib: a randomised controlled trial. Lancet. 2006;368(9544):1329-38.

20. Demetri GD, Reichardt P, Kang YK, Blay JY, Rutkowski P, Gelderblom H, et al. Efficacy and safety of regorafenib for advanced gastrointestinal stromal tumours after failure of imatinib and sunitinib (GRID): an international, multicentre, randomised, placebo-controlled, phase 3 trial. Lancet. 2013;381(9863):295-302.

21. European society for medical oncology. Gastrointestinal stromal tumors: ESMO Clinical Practice Guidelines for diagnosis, treatment and follow-up Ann Oncol. 2012;23 Suppl 7:vii49-55.

22. Woodall 3rd CE, Brock GN, Fan J, Byam JA, Scoggins CR, McMasters KM, et al. An evaluation of 2537 gastrointestinal stromal tumors for a proposed clinical staging system. Arch Surg. 2009;144(7):670-8.

23. Joensuu H, Vehtari A, Riihimaki J, Nishida T, Steigen SE, Brabec P, et al. Risk of recurrence of gastrointestinal stromal tumour after surgery: an analysis of pooled population-based cohorts. Lancet Oncol. 2012;13(3):265-74.

24. Gold JS, Gonen M, Gutierrez A, Broto JM, Garcia-del-Muro X, Smyrk TC, et al. Development and validation of a prognostic nomogram for recurrence-free survival after complete surgical resection of localised primary gastrointestinal stromal tumour: a retrospective analysis. Lancet Oncol. 2009;10(11):1045-52

\section{Submit your next manuscript to BioMed Central and take full advantage of:}

- Convenient online submission

- Thorough peer review

- No space constraints or color figure charges

- Immediate publication on acceptance

- Inclusion in PubMed, CAS, Scopus and Google Scholar

- Research which is freely available for redistribution 